INTERNATIONAL HIGHER EDUCATION - NUMBER 66 WINTER 2012 Pages 33-35.

\title{
Canada's Egalitarian Debate
}

Daniel Zaretsky

Daniel Zaretsky is chief ideas officer of Higher-Edge, a Toronto-based international higher education consulting firm. E-mail: dani@higher-edge.com.

Some countries with much smaller populations, than Canada's 35 million, have developed a sharply differentiated or tiered university system. But Canada's university system evinces a different prevailing ethos. It aspires to lesser differences overall-in terms of calibre of teaching, content, research, and facilities. Thus, last year, Canada's leading national English-language magazine, Maclean's, reported on Canada's Big Five universities crying out for more research funding. Why did the article elicit objections from other Canadian universities? And, anyway, why does Canada have a Big Five and not a Best Five?

\section{No ELITE TIER OF UNIVERSITIES}

For a country with 10 percent of the US population, it has proportionately far fewer institutions. There are only about 100 mainly degree-granting institutions in Canada, compared to about 4,000 in the United States. The Canadian system is virtually entirely provincially funded. Tuitions are heavily regulated, and provinces offer needs-based loans and grants. Private universities are virtually unheard of. The few that exist have tiny student bodies, are generally obscure, and are not research in nature. Canada has an unusually high proportion of its 
universities as research universities and a similarly unusual proportion of all of these in small population centers.

\section{TUITION-LOW AND STAYING LOW}

What is the tuition fee import of these differences? Almost all bachelor's degrees in Canada cost Canadians between $C \$ 6,000$ and 8,000 for annual tuition (with almost all the exceptions lower-as low as $\mathrm{C} \$ 2,000)$. Tuition differences do not reflect intraprovincial or interprovincial caliber-or even perceived caliber-but simply involve the budget judgment of one province, as distinct from another. Yet, Canada's bachelor's degree programs are highly respected outside Canada, and its professional programs and medical and law schools are considered first rate by the loftiest of US vantage points (for example, all engineering schools are accredited by the ABET (Accreditation Board for Engineering and Technology).

McGill University is one of the self-annointed "Big 5" (along with the University of Toronto, Université de Montréal, the University of British Columbia, and the University of Alberta). It is one of the few Canadian universities that can lay claim to attracting a sizeable proportion of students from all over Canada (and the United States). Yet, a bachelor's degree costs Quebec residents barely $\mathrm{C} \$ 2,000$ a year!

Since tuition prices are limited by the provinces, Canadian institutions have no undue financial incentive to make big investments in branding. Dressing up the image might help command more students or a somewhat better academic profile for the incoming class. But this is not the same conception as having the option to charge more in fees as demand and appeal strengthens. 


\section{COMMUTER COUNTRY}

It is no surprise, then, that another by-product of the Canadian system means that it is exceedingly commonplace for university-bound students in cities across Canada, with small populations, to choose to study near the home region. A typical Canadian will not think Canada's Big 5 universities—or the US top 10, for that matter-would teach biology or psychology, which are qualitatively more challenging than in the many choices they have within commuter distance.

No Canadian university has a national brand image that compares remotely with the national brand image of Harvard or of the Massachusetts Institute of Technology. In the international domain, Canadian universities lag very much behind a long list of US counterparts in name recognition. As a result, this system makes it likely that top students will be well-distributed across the country's institutions.

\section{LOWER-STRESS HIGH SCHOOL}

The absence of big brand differences, a further implication of the Canadian system, is that Canadian high schoolers may work hard but are not overly stressed. This is not to say there is not any high school striving or competitiveness. Certainly, some bachelor programs at a university with limited enrollment require extraordinary achievement to gain entry (and usually do not cost more). But these demands are few and far between.

For example, fine mathematics and physics students have ample engineering spaces across the country and, for most, close to home. For a host of 
individual reasons, large numbers of students routinely turn down one or more of the Big Five, to attend another institution.

Though high school standardization and scoring is on the wane, for the most part, Canadian high school grades are taken at face value, without further validation required. There is no SAT (Scholastic Assessment Test) equivalent or an entrance exam system. While exceptions exist, most university programs simply require only a submission of high school results.

Because top students study at their own local university, the overall competitive framework is not skewed. The ultra-competitiveness is saved for postbachelor programs—or medicine, dentistry, law, and a wide range of thesisbased master's dreams.

So, if there are student protests, it is not over the absence of Ivy League institutions in Canada, but rather over the fact that $C \$ 5,000$ or 7,000 is still a lot of money to pay for annual tuition. Even at these prices, tuition costs remain lively issues in provincial elections.

\section{THE Big Five Aspiration}

The protestations that do emanate come from institutions like Canada's so-called Big Five universities (located in its most-populous urban centers). These institutions feel hamstrung from competing in research, with the world's top echelon of research universities. This is largely due to the "burden" as faculty would see it of taking on huge classes of undergraduate students, which dwarf those of many prominent US research universities.

The US system has critiqued itself over offering too few research professors as instructors in undergraduate courses, especially in its elite 
institutions. In Canada, the norm is that research faculty commit fully to bachelor's-degree-level instruction. Good for teaching and students, not so good for enabling faculty to focus on research.

To Canada's large research institutions, they would be happier if many of Canada's other universities taught more undergraduate students, leaving more of the research time, and money, to them. The smaller institutions feel they have proven worthy of the research monies they have garnered and are unconvinced a shift in resources to the biggest of Canada's universities would be better for Canada-i.e., the Big Five are not necessarily the Best Five.

\section{SOCIETAL TRADE-OFFS}

The fault line is ultimately whether having a top tier (far from assured) of superfocused research universities is worth the trade-off. Is it in Canada's best interests to cluster research more in its ultraurban areas and fund less of its research in smaller urban areas? Does it serve the public to have more students studying less under research professors, at research universities or, indeed, more students in programs where no research companion is there?

Canada produces excellent research, but it is geographically distributed. Indeed, research production might be greater were it clustered and if the best researchers were relieved much more, or entirely, from teaching obligations. From the public-vantage point, the trade-off is whether to invest locally or concentrate funding in a few top institutions.

As the land of a single standard of state-funded health care for all, Canadians are generally apt to trade off a little excellence for a lot more equity. 